\title{
Survival of patients with symptom- and screening-detected colorectal cancer
}

\author{
Hermann Brenner ${ }^{1,2,3}$, Lina Jansen ${ }^{1}$, Alexis Ulrich ${ }^{4}$, Jenny Chang-Claude ${ }^{5}$, Michael \\ Hoffmeister $^{1}$ \\ ${ }^{1}$ Division of Clinical Epidemiology and Aging Research, German Cancer Research Center (DKFZ), Heidelberg, Germany \\ ${ }^{2}$ Division of Preventive Oncology, German Cancer Research Center (DKFZ), Heidelberg, Germany \\ ${ }^{3}$ German Cancer Consortium (DKTK), German Cancer Research Center (DKFZ), Heidelberg, Germany \\ ${ }^{4}$ Department of General, Visceral and Transplantation Surgery, University of Heidelberg, Heidelberg, Germany \\ ${ }^{5}$ Unit of Genetic Epidemiology, German Cancer Research Center (DKFZ), Heidelberg, Germany \\ Correspondence to: Hermann Brenner, e-mail h.brenner@dkfz.de
}

Keywords: colonoscopy, colorectal cancer, fecal occult blood test, screening, survival

Received: March 07, $2016 \quad$ Accepted: April 26, $2016 \quad$ Published: May 17, 2016

\section{ABSTRACT}

Background: An increasing proportion of colorectal cancer (CRC) patients are diagnosed by screening rather than symptoms.

Aims: We aimed to assess and compare prognosis of patients with screendetected CRC and symptom-detected CRC.

Methods: Overall and CRC specific mortality over a median follow-up of 4.8 years was assessed according to mode of diagnosis (symptoms, screening colonoscopy, fecal occult blood test [FOBT], other) in a multi-center cohort of 2,450 CRC patients aged 50-79 years recruited in Germany in 2003-2010.

Results: $68 \%, 11 \%$ and $10 \%$ were detected by symptoms, screening colonoscopy and FOBT, respectively. The screen-detected cancers had a more favorable stage distribution than the symptom-detected cancers ( $68 \%$ versus $50 \%$ in stage I or II). Age- and sex adjusted hazard ratios (HRs) of total mortality with $95 \%$ confidence intervals (95\% CIs) compared to symptom-detected cancers were 0.35 (0.24-0.50) and $0.36(0.25-0.53)$ for screening colonoscopy and FOBT detected CRCs, respectively. HRs were only slightly attenuated and remained highly significant after adjustment for stage and multiple other covariates $(0.50(0.34-0.73)$ and $0.54(0.37-0.80)$, respectively). Even stronger associations were seen for CRC specific mortality. Patients with screen-detected stage III CRC had as good CRC specific survival as patients with symptom-detected stage I or II CRC.

Conclusions: Patients with screen-detected CRC have a very good prognosis far beyond the level explained by their more favorable stage distribution. Mode of detection is an important, easy-to-obtain proxy indicator for favorable diagnosis beyond earlier stage at diagnosis and as such may be useful for risk stratification in treatment decisions.

\section{INTRODUCTION}

Screening for colorectal cancer (CRC) is employed in an increasing number of countries due to its proven efficacy in reducing CRC incidence and mortality [1-9], and an increasing share of CRC cases is diagnosed by screening rather than by symptoms. It is to be expected that patients with screen-detected CRC have better prognosis than patients with symptom-detected CRC due to earlier diagnosis and potentially other favorable tumor or host characteristics. However, it is unclear to what extent survival advantages persist within stages at diagnosis. Direct evidence on overall and stage-specific survival expectations of patients with screen-detected CRC is surprisingly sparse. Such evidence would though be of major clinical and public health interest for 
several reasons: First, it may alleviate the fear of having a diagnosis of $\mathrm{CRC}$ at screening which may be a major obstacle for people to undergo CRC screening. Second, it may alleviate fears of patients after a CRC diagnosis at screening. Third, it may enhance the basis for clinical decision making.

In this manuscript, we provide a detailed assessment of prognosis of CRC patients according to type of diagnosis (detection by symptoms, screening colonoscopy, fecal occult blood test [FOBT], or otherwise) in a large multi-center cohort of CRC patients from Germany for whom detailed information on the diagnostic process was obtained.

\section{MATERIALS AND METHODS}

\section{Study design and study population}

In Germany, screening colonoscopy is offered to the average risk population from age 55 on. Screening by (guaiac based) FOBT is offered annually at ages 50 to 54 . From age 55 on, FOBT every two years is offered as an alternative to screening colonoscopy. To assess the impact of screening, the DACHS (Darmkrebs: Chancen der Verhütung durch Screening) study was initiated in the Rhine-Neckar area of Germany in 2003. DACHS is a population-based case-control study with additional comprehensive follow-up of cases. Details of the study design and data collection have been reported previously [10-12]. Briefly, patients with a first diagnosis of CRC (ICD 10 codes C18-C20) aged 30 years or older are recruited in all of the 22 hospitals providing CRC surgery in the study region (approximately 2 million inhabitants). Matched controls are randomly selected from population registries. The study was approved by the ethics committees of the Medical Faculty of the University of Heidelberg and of the Medical Chambers of BadenWürttemberg and Rhineland-Palatinate. Written informed consent is obtained from each participant. Participants for the current analysis were selected from 3,146 cases recruited from 2003 to 2010 and followed with respect to survival to 2013 .

\section{Data collection}

Personal interviews with cases were conducted by trained interviewers using a standardized questionnaire. Interviews were conducted during hospital stay, typically a few days after surgery, wherever possible, or after hospital discharge at the patients' homes otherwise. In addition, medical data were extracted from hospital charts. The interviews lasted for about one hour and addressed potential CRC risk factors, preventive factors and prognostic factors in great detail. In addition, detailed information was collected on history of CRC screening and the basis for the current CRC diagnosis. In particular, patients were asked if the diagnosis was made by work-up of symptoms, by a screening examination or incidentally (e.g. in the context of medical examination for other reasons). If the cancer was detected by screening, the type and sequence of screening examinations was ascertained.

Data extracted from medical charts include tumor stage and location in particular. Three years after diagnosis, standardized information on CRC therapy was obtained from the physicians of the patients. Three and 5 years after diagnosis, vital status was ascertained through systematic follow-up by record linkage with population registries. For deceased patients, cause of death was extracted from death certificates which were obtained from local public health authorities.

\section{Statistical analysis}

For statistical analysis, the following consecutive exclusions were made (numbers and reasons given in parentheses): $<50$ or $>=80$ years of age $(n=664$; screening not commonly offered or recommended for the average risk population at these ages), history of inflammatory bowel disease ( $\mathrm{n}=19$; frequent surveillance colonoscopies due to increased risk of CRC), missing information on the mode of CRC detection ( $\mathrm{n}=2$ ), and missing follow-up data $(n=11)$. After these exclusions, there remained 2,450 cases for the analysis.

We first described cases according to age, sex, education, stage (using the Union Internationale Contre le Cancer [UICC] classification), site (proximal colon, cecum to transverse colon; distal colon, left flexure to sigmoid colon; rectum) and mode of detection (symptoms; screening colonoscopy; FOBT; other, such as incidental detection in the course of other diagnostic measures) of the cancer. Differences in age, sex, education, stage, and site distributions by mode of detection were assessed by Chi square tests.

Next, we assessed overall and CRC specific survival according to mode of detection. Survival time was calculated from the day of diagnosis to the day of death (deceased patients) or censored at the date of the last follow-up. In cause specific survival analyses survival time was censored at the day of death from other reasons.

Survival was compared by mode of detection using direct adjusted survival curves (adjusted for age and sex). In addition, Cox proportional hazards models were run to evaluate the association of mode of detection with survival outcomes using various levels of adjustment: Model 1 adjusted for sociodemographic variables only (sex, age, education). Model 2 additionally adjusted for key tumor characteristics, i.e., stage and location. In order to assess potential variation of results according to specific treatments, Cox proportional hazards models were repeated after excluding 304 patients who had received neoadjuvant therapy in sensitivity analyses. Furthermore, we carried out specific analyses on CRC specific survival 
for subgroups defined by tumor stage and location, by conduct of chemotherapy among stage II and stage III patients, and by sex and age. In all Cox models, the proportional hazards assumption was checked by testing for interaction of the covariates with follow-up time and interaction terms were added as needed.

All statistical analyses were carried out using SAS statistical software, version 9.3 (SAS Institute Inc., Cary, North Carolina). An alpha level of 0.05 was employed for statistical tests.

\section{RESULTS}

Table 1 shows characteristics of the study population which included 1520 (62\%) male and 930 (38\%) female patients. The majority of patients were between 60 and 79 years old (82\%; median: 68 years), were diagnosed at stage II or III (62\%), and had their cancer detected by symptoms (68\%). Screening colonoscopy, FOBT and other reasons led to the diagnosis in approximately $10 \%$ each.

Patients whose cancer was detected by screening colonoscopy more often had higher education than patients with symptom-detected cancer (Table 2). Furthermore, their cancer was detected much more often in stage I (50\% versus $17 \%)$, and located in the colon (69\% versus $53 \%$ ). FOBT detected cancers also had a more favourable stage distribution than symptom-detected cancers, with only $4 \%$ of cancers detected in stage IV, compared to $17 \%$ for symptom-detected cancers and 5\% for screening colonoscopy-detected cancers. However, the proportion of stage I cancers was lower than among screening colonoscopy-detected cancers.

During a median follow-up time of 4.8 years (interquartile range: 3.0 to 5.1 years), 590 (24\%) patients died, of whom 461 (78\%) died from CRC. Direct adjusted survival curves are shown in Figure 1. Patients whose cancer was detected by screening colonoscopy or FOBT had substantially higher overall survival and CRC specific survival 5 years after diagnosis $(>85 \%$ and $>90 \%$, respectively) than patients whose cancer was detected by symptoms or otherwise $(<70 \%$ and $<75 \%$, respectively). After adjustment for age, sex and education, patients whose cancer was detected by screening colonoscopy had a $65 \%$ lower total mortality than patients with symptom-detected cancers (hazard ratio, $\mathrm{HR}, 0.35,95 \%$ confidence interval, 95\% CI, 0.24 0.50 ) (Table 3). A 50\% mortality reduction persisted even after additional control for stage and location of the cancer (HR 0.50, 95\% CI 0.34-0.73). Similarly decreased total mortality was seen for patients whose cancer was detected by FOBT. Even stronger reductions were seen for CRC mortality, with fully adjusted hazard ratios of 0.36 (95\% CI 0.21-0.60) and 0.47 (95\% CI 0.29-0.77) for patients with screening colonoscopy and FOBTdetected cancers, respectively. By contrast, no difference was seen in mortality from other causes between patients with screen-detected and symptom-detected cancer. Sensitivity analyses excluding 304 patients who had received neoadjuvant therapy did not materially change any of the observed associations (fully adjusted HRs (95\% CIs) for CRC mortality: 0.38 (95\% CI 0.23-0.64) and 0.48 (95\% CI $0.29-0.79)$ for colonoscopy- and FOBT detected cancers, respectively). The same applies to sensitivity analyses specifically adjusting for $\mathrm{T}$ - and $\mathrm{N}$-status in addition to UICC stage (fully adjusted HRs (95\% CIs) for CRC mortality: 0.37 (95\% CI 0.21-0.64) and 0.52 (95\% CI 0.31-0.85) for colonoscopy- and FOBT detected cancers, respectively).

Given very similar results for survival of patients with screening colonoscopy and FOBT-detected cancers both groups were combined in further, subgroup specific analyses. Strongly reduced CRC specific mortality for patients with screening colonoscopy or FOBT-detected compared to symptom-detected cancers was consistently seen even after full adjustment for all subgroups defined by tumor stage or location (Table 4, Figure 1, Panels D, E, F), sex or age (Table 5). With a $74 \%$ lower CRC specific mortality for screen-detected compared to symptomsdetected cancers, the association was particularly strong among stage II-III patients who received chemotherapy. Additional subgroup analyses among stage III patients by number of affected lymph nodes (N1: 1-3 lymph nodes, N2: 4+ lymph nodes) confirmed substantially lower CRC mortality for patients with screen-detected CRC than for patients with symptom-detected CRC within both subgroups (N1: HR 0.34, 95\% CI 0.14-0.81; N2: HR 0.39, 95\% CI 0.40-1.10). Among patients with screen-detected stage III CRC, 5-year CRC specific survival was as high (slightly above 90\%) as among patients with symptomdetected stage I or II CRC (Figure 1, Panels D and E). The small number of patients with screen-detected stage IV CRC had approximately two-fold higher 5-year CRCspecific survival (40\% versus 20\%) and 2-fold longer median CRC-specific survival (4 versus 2 years) compared to patients with symptom-detected stage IV CRC (Figure 1, Panel F).

\section{DISCUSSION}

In this large cohort of patients with $\mathrm{CRC}$ recruited in the context of a population-based case-control study in Southern Germany, patients whose cancer was detected by screening colonoscopy or FOBT had strongly enhanced overall survival and even more strongly enhanced CRC specific survival compared to patients with symptomdetected cancer. Even though survival differences were partly explained by the more favourable stage distribution of patients with screening detected cancers, the largest share of the survival advantages persisted even after control for CRC stage, and large survival advantages were seen within each stage. Patients with screen-detected stage 
Table 1: Characteristics of the study population

\begin{tabular}{|c|c|c|c|c|c|c|}
\hline \multirow[t]{2}{*}{ Characteristic } & \multicolumn{2}{|c|}{ Men } & \multicolumn{2}{|c|}{ Women } & \multicolumn{2}{|c|}{ Total } \\
\hline & $\mathbf{n}$ & $\%$ & $\mathbf{N}$ & $\%$ & $\mathbf{n}$ & $\%$ \\
\hline \multicolumn{7}{|l|}{ Age } \\
\hline $50-59$ years & 273 & $18 \%$ & 175 & $19 \%$ & 448 & $18 \%$ \\
\hline $60-69$ years & 636 & $42 \%$ & 363 & $39 \%$ & 999 & $41 \%$ \\
\hline 70-79 years & 611 & $40 \%$ & 392 & $42 \%$ & 1003 & $41 \%$ \\
\hline \multicolumn{7}{|l|}{ Education $^{a}$} \\
\hline$\leq 9$ years & 1057 & $70 \%$ & 651 & $70 \%$ & 1708 & $70 \%$ \\
\hline $10-11$ years & 204 & $13 \%$ & 178 & $19 \%$ & 382 & $16 \%$ \\
\hline $12+$ years & 259 & $17 \%$ & 97 & $11 \%$ & 356 & $14 \%$ \\
\hline \multicolumn{7}{|l|}{ Cancer stage $^{b}$} \\
\hline I & 365 & $24 \%$ & 210 & $23 \%$ & 575 & $23 \%$ \\
\hline II & 459 & $30 \%$ & 289 & $31 \%$ & 748 & $31 \%$ \\
\hline III & 460 & $31 \%$ & 304 & $33 \%$ & 764 & $31 \%$ \\
\hline IV & 231 & $15 \%$ & 125 & $13 \%$ & 356 & $15 \%$ \\
\hline \multicolumn{7}{|l|}{ Cancer site ${ }^{c}$} \\
\hline Proximal colon & 399 & $26 \%$ & 332 & $36 \%$ & 731 & $30 \%$ \\
\hline Distal colon & 419 & $28 \%$ & 268 & $29 \%$ & 687 & $28 \%$ \\
\hline Rectum & 699 & $46 \%$ & 327 & $35 \%$ & 1026 & $42 \%$ \\
\hline \multicolumn{7}{|l|}{ Mode of detection } \\
\hline Symptoms & 997 & $66 \%$ & 673 & $73 \%$ & 1670 & $68 \%$ \\
\hline $\begin{array}{l}\text { Screening } \\
\text { colonoscopy }\end{array}$ & 183 & $12 \%$ & 96 & $10 \%$ & 279 & $11 \%$ \\
\hline FOBT & 168 & $11 \%$ & 75 & $8 \%$ & 243 & $10 \%$ \\
\hline Other & 172 & $11 \%$ & 86 & $9 \%$ & 258 & $11 \%$ \\
\hline
\end{tabular}

FOBT, fecal occult blood test

${ }^{\text {a }}$ Information missing for 4 patients.

${ }^{\mathrm{b}}$ Information missing for 7 patients.

${ }^{\mathrm{c}}$ Information missing for 6 patients.

III CRC had as good CRC specific survival as patients with symptom-detected stage I or II CRC.

Our findings of more favourable stage distribution among screen-detected cancers than among symptomdetected cancers are consistent with previous reports from various countries including Germany [e.g. 13-17]. Higher survival rates of patients with screen-detected CRC than of patients with symptom-detected CRC have also been repeatedly reported [16-25], but few studies have addressed survival by stage, and the survival advantage has primarily been attributed to more favorable stage distribution. However, in agreement with our findings, Mapp et al found a significant survival advantage in patients with screen-detected cancers in the Nottingham FOBT trial which persisted after control for tumor stage [19]. In two studies ( $\mathrm{n}=633$ and 514, respectively) conducted in the context of the FOBT based British Bowel Cancer Screening Programme, survival advantages for screen-detected cancers over symptom-detected cancers were likewise observed even in stage-specific and stageadjusted analyses [22, 24]. Similar results were recently reported for screening colonoscopy detected colon cancer in a single center study $(n=1,071)$ from the US [25]. In our multi-center study from Germany $(n=2,450)$, we observed similarly strong survival advantages for patients with either FOBT or screening colonoscopy-detected CRC 
Table 2: Association of mode of detection with patient and tumor characteristics

\begin{tabular}{|c|c|c|c|c|c|c|c|c|c|c|c|}
\hline \multirow[t]{3}{*}{ Characteristic } & \multicolumn{11}{|c|}{ Mode of detection } \\
\hline & \multicolumn{2}{|c|}{ Symptoms } & \multicolumn{2}{|c|}{$\begin{array}{l}\text { Screening } \\
\text { colonoscopy }\end{array}$} & \multirow[t]{2}{*}{ p-value ${ }^{a}$} & \multicolumn{2}{|c|}{ FOBT } & \multirow[t]{2}{*}{ p-value ${ }^{a}$} & \multicolumn{2}{|c|}{ Other } & \multirow[t]{2}{*}{ p-value ${ }^{a}$} \\
\hline & $\mathbf{n}$ & $\%$ & n & $\%$ & & $\mathbf{n}$ & $\%$ & & n & $\%$ & \\
\hline \multicolumn{12}{|l|}{ Age } \\
\hline $50-59$ & 322 & $19 \%$ & 40 & $14 \%$ & \multirow{3}{*}{0.037} & 47 & $19 \%$ & \multirow{3}{*}{0.43} & 39 & $15 \%$ & \multirow{3}{*}{0.066} \\
\hline $60-69$ & 679 & $41 \%$ & 134 & $48 \%$ & & 89 & $37 \%$ & & 97 & $38 \%$ & \\
\hline $70-79$ & 669 & $40 \%$ & 105 & $38 \%$ & & 107 & $44 \%$ & & 122 & $47 \%$ & \\
\hline \multicolumn{12}{|l|}{$\operatorname{Sex}$} \\
\hline Men & 997 & $60 \%$ & 183 & $66 \%$ & \multirow{2}{*}{0.062} & 168 & $69 \%$ & \multirow{2}{*}{0.005} & 172 & $67 \%$ & \multirow{2}{*}{0.033} \\
\hline Women & 673 & $40 \%$ & 96 & $34 \%$ & & 75 & $31 \%$ & & 86 & $33 \%$ & \\
\hline \multicolumn{12}{|l|}{ Education } \\
\hline$\leq 9$ years & 1189 & $71 \%$ & 175 & $63 \%$ & \multirow{3}{*}{0.003} & 163 & $67 \%$ & \multirow{3}{*}{0.262} & 181 & $67 \%$ & \multirow{3}{*}{0.773} \\
\hline $10-11$ years & 258 & $15 \%$ & 47 & $17 \%$ & & 39 & $16 \%$ & & 38 & $16 \%$ & \\
\hline $12+$ years & 220 & $13 \%$ & 57 & $20 \%$ & & 41 & $17 \%$ & & 38 & $17 \%$ & \\
\hline \multicolumn{12}{|l|}{ Cancer stage } \\
\hline I & 291 & $17 \%$ & 139 & $50 \%$ & \multirow{4}{*}{$<0.001$} & 83 & $34 \%$ & \multirow{4}{*}{$<0.001$} & 62 & $24 \%$ & \multirow{4}{*}{0.048} \\
\hline II & 545 & $33 \%$ & 47 & $17 \%$ & & 82 & $34 \%$ & & 74 & $29 \%$ & \\
\hline III & 547 & $33 \%$ & 76 & $27 \%$ & & 67 & $28 \%$ & & 74 & $29 \%$ & \\
\hline IV & 283 & $17 \%$ & 15 & $5 \%$ & & 10 & $4 \%$ & & 48 & $18 \%$ & \\
\hline \multicolumn{12}{|l|}{ Cancer site } \\
\hline Prox. colon & 428 & $26 \%$ & 97 & $35 \%$ & \multirow{3}{*}{$<0.001$} & 88 & $36 \%$ & \multirow{3}{*}{$<0.001$} & 118 & $46 \%$ & \multirow{3}{*}{$<0.001$} \\
\hline Distal colon & 449 & $27 \%$ & 96 & $34 \%$ & & 72 & $30 \%$ & & 70 & $28 \%$ & \\
\hline Rectum & 790 & $47 \%$ & 86 & $31 \%$ & & 83 & $34 \%$ & & 67 & $26 \%$ & \\
\hline
\end{tabular}

FOBT, fecal occult blood test

${ }^{a} \mathrm{p}$-value for difference from participants whose cancer was detected by symptoms

which were only reduced to a small extent and remained highly statistically significant after control for stage in multivariable analysis.

Higher survival of screening detected cases compared to symptom detected cases does not by itself prove any beneficial effects of screening. On the contrary, any screening leading to earlier diagnosis of cancer would be expected to go along with longer survival after diagnosis even if total mortality in the screened and unscreened population remained the same. In such a situation, the apparently longer survival after diagnosis might merely reflect lead time, i.e. advancement of the diagnosis by screening, unless the earlier diagnosis also enhances chances of cure. However, for CRC, chances of cure are strongly stage dependent, and the strong shift of the stage distribution towards earlier stages by colonoscopy or FOBT screening is expected to go along with substantially enhanced chances of cure.

Nevertheless, earlier diagnosis was not the only reason for the substantially enhanced survival of patients with screen-detected cancers because a strong survival advantage of this group persisted even after control for cancer stage and was observed for every stage in stagespecific analyses. Several mechanisms might explain this finding. First, confounding by stage might not be fully accounted for by the relatively crude classification of stage which is an extremely strong predictor of prognosis among CRC patients. However, results remained essentially unchanged in sensitivity analyses specifically adjusting for T- and N-status in addition to UICC stage, and very similar results were obtained after further stratification of stage III cancers according to number of affected lymph 


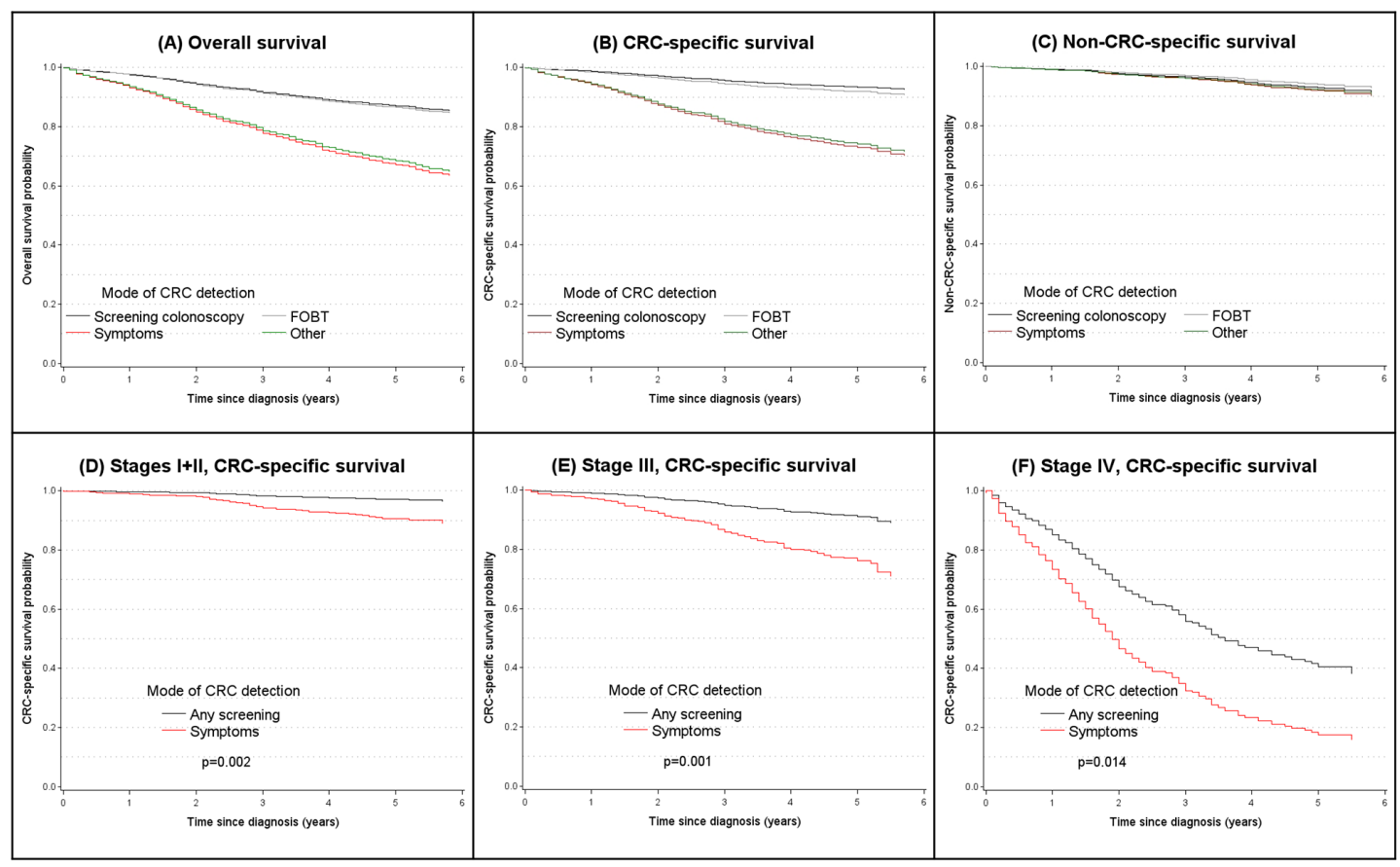

Figure 1: Direct adjusted survival curves according to mode of cancer detection for A. overall and B. CRC-specific survival, $\mathbf{C}$. non-CRC-specific survival and D, E, F. according to mode of detection and stage at diagnosis (all survival curves were adjusted for age and sex).

Table 3: Hazard ratios for total, CRC specific and other mortality according to mode of detection

\begin{tabular}{|c|c|c|c|c|c|c|c|}
\hline \multirow{3}{*}{$\begin{array}{l}\text { Outcome, mode of } \\
\text { detection }\end{array}$} & \multicolumn{3}{|c|}{ Mortality } & \multicolumn{4}{|c|}{ Hazard Ratios } \\
\hline & \multirow[t]{2}{*}{ Deaths } & \multirow[t]{2}{*}{$\begin{array}{c}\text { Person- } \\
\text { years }\end{array}$} & \multirow[t]{2}{*}{$\begin{array}{l}\text { Rate per } 1000 \\
\text { person-yrs }\end{array}$} & \multicolumn{2}{|c|}{$\begin{array}{l}\text { Adjusted for age, sex, } \\
\text { education }{ }^{\text {a }}\end{array}$} & \multicolumn{2}{|c|}{ Fully adjusted $^{\mathrm{b}}$} \\
\hline & & & & HR & $95 \% \mathrm{CI}$ & HR & $95 \% \mathrm{CI}$ \\
\hline \multicolumn{8}{|l|}{ Total mortality } \\
\hline Symptoms & 461 & 5815 & 79.3 & 1.00 & Ref. & 1.00 & Ref. \\
\hline Screening colonoscopy & 30 & 1073 & 28.0 & 0.35 & $(0.24-0.50)$ & 0.50 & $(0.34-0.73)$ \\
\hline FOBT & 29 & 971 & 29.9 & 0.36 & $(0.25-0.53)$ & 0.54 & $(0.37-0.80)$ \\
\hline Other & 70 & 899 & 77.9 & 0.94 & $(0.73-1.21)$ & 0.86 & $(0.66-1.11)$ \\
\hline \multicolumn{8}{|l|}{ CRC mortality } \\
\hline Symptoms & 373 & 5815 & 64.1 & 1.00 & Ref. & 1.00 & Ref. \\
\hline Screening colonoscopy & 15 & 1073 & 14.0 & 0.21 & $(0.13-0.36)$ & 0.36 & $(0.21-0.60)$ \\
\hline FOBT & 17 & 971 & 17.5 & 0.27 & $(0.17-0.44)$ & 0.47 & $(0.29-0.77)$ \\
\hline Other & 56 & 899 & 62.3 & 0.93 & $(0.70-1.23)$ & 0.85 & $(0.63-1.13)$ \\
\hline \multicolumn{8}{|l|}{ Non CRC mortality } \\
\hline Symptoms & 88 & 5815 & 15.1 & 1.00 & Ref. & 1.00 & Ref. \\
\hline Screening colonoscopy & 15 & 1073 & 14.0 & 0.92 & $(0.53-1.59)$ & 0.94 & $(0.53-1.67)$ \\
\hline FOBT & 12 & 971 & 12.4 & 0.73 & $(0.40-1.33)$ & 0.74 & $(0.40-1.37)$ \\
\hline Other & 14 & 899 & 15.6 & 0.99 & $(0.56-1.74)$ & 0.96 & $(0.54-1.72)$ \\
\hline
\end{tabular}

FOBT, fecal occult blood test; HR, hazard ratio, 95\% CI, 95\% confidence interval

a Adjusted for age, sex, and education, and for a time-dependent effect of age and sex.

${ }^{\mathrm{b}}$ Additionally adjusted for stage and location of the cancer, and for time-dependent effects of stage and location. 
Table 4: Hazard ratios for CRC-specific mortality according to mode of detection and stage at diagnosis and location of tumor

\begin{tabular}{|c|c|c|c|c|c|}
\hline \multirow{2}{*}{$\begin{array}{l}\text { Patient / tumor characteristics, } \\
\text { mode of detection }\end{array}$} & \multirow[t]{2}{*}{ Deaths } & \multirow[t]{2}{*}{ Person-years } & \multirow{2}{*}{$\begin{array}{c}\text { Rate per } 1,000 \\
\text { person-yrs }\end{array}$} & \multicolumn{2}{|c|}{ Fully adjusted hazard ratio ${ }^{2}$} \\
\hline & & & & HR & $95 \% \mathrm{CI}$ \\
\hline \multicolumn{6}{|l|}{ Stage $I+I I$} \\
\hline Symptoms & 60 & 3225 & 18.6 & 1.00 & Ref. \\
\hline Any screening & 8 & 1410 & 5.7 & 0.29 & $(0.14-0.61)$ \\
\hline Other & 5 & 528 & 9.5 & 0.46 & $(0.18-1.17)$ \\
\hline \multicolumn{6}{|l|}{ Stage III } \\
\hline Symptoms & 102 & 1983 & 51.4 & 1.00 & Ref. \\
\hline Any screening & 10 & 547 & 18.3 & 0.33 & $(0.17-0.64)$ \\
\hline Other & 14 & 266 & 52.6 & 0.86 & $(0.47-1.57)$ \\
\hline \multicolumn{6}{|l|}{ Stage IV } \\
\hline Symptoms & 209 & 597 & 350.1 & 1.00 & Ref. \\
\hline Any screening & 14 & 72 & 194.4 & 0.52 & $(0.30-0.90)$ \\
\hline Other & 37 & 105 & 352.4 & 0.92 & $(0.64-1.31)$ \\
\hline \multicolumn{6}{|c|}{ Stage II-III patients who received chemotherapy ${ }^{b}$} \\
\hline Symptoms & 98 & 2452 & 40.0 & 1.00 & Ref. \\
\hline Any screening & 7 & 583 & 12.0 & 0.26 & $(0.12-0.56)$ \\
\hline Other & 11 & 270 & 40.7 & 0.69 & $(0.35-1.36)$ \\
\hline \multicolumn{6}{|c|}{$\begin{array}{l}\text { Stage II-III patients who did not receive } \\
\text { chemotherapy }\end{array}$} \\
\hline Symptoms & 84 & 2443 & 34.4 & 1.00 & Ref. \\
\hline Any screening & 10 & 621 & 16.1 & 0.45 & $(0.23-0.87)$ \\
\hline Other & 7 & 312 & 22.4 & 0.67 & $(0.30-1.48)$ \\
\hline \multicolumn{6}{|l|}{ Proximal colon } \\
\hline Symptoms & 112 & 1380 & 81.2 & 1.00 & Ref. \\
\hline Any screening & 11 & 721 & 15.3 & 0.32 & $(0.17-0.60)$ \\
\hline Other & 22 & 431 & 51.0 & 0.65 & $(0.40-1.04)$ \\
\hline \multicolumn{6}{|l|}{ Distal colon } \\
\hline Symptoms & 91 & 1627 & 55.9 & 1.00 & Ref. \\
\hline Any screening & 10 & 670 & 14.9 & 0.47 & $(0.24-0.93)$ \\
\hline Other & 20 & 225 & 88.9 & 1.40 & $(0.85-2.31)$ \\
\hline \multicolumn{6}{|l|}{ Rectum } \\
\hline Symptoms & 168 & 2799 & 60.0 & 1.00 & Ref. \\
\hline Any screening & 11 & 653 & 16.8 & 0.47 & $(0.25-0.86)$ \\
\hline Other & 14 & 230 & 60.9 & 0.70 & $(0.40-1.22)$ \\
\hline
\end{tabular}

FOBT, fecal occult blood test; HR, hazard ratio; $95 \%$ CI, 95\% confidence interval

${ }^{a}$ Adjusted for age, sex, education, stage and location of the cancer, and for time-dependent effects of age, sex, stage and location.

${ }^{\mathrm{b}}$ Colon cancer patients who received chemotherapy after surgery for treatment of primary cancer; rectum cancer patients who received neoadjuvant therapy before surgery and/or chemotherapy after surgery for treatment of primary cancer. 
Table 5: Hazard ratios for CRC-specific mortality according to mode of detection and by age and sex

\begin{tabular}{|c|c|c|c|c|c|}
\hline \multirow{2}{*}{$\begin{array}{l}\text { Patient characteristics, } \\
\text { mode of detection }\end{array}$} & \multirow[t]{2}{*}{ Deaths } & \multirow[t]{2}{*}{ Person-years } & \multirow{2}{*}{$\begin{array}{c}\text { Rate per } 1,000 \\
\text { person-yrs }\end{array}$} & \multicolumn{2}{|c|}{ Fully adjusted hazard ratio } \\
\hline & & & & HR & $95 \%$ CI \\
\hline \multicolumn{6}{|l|}{ Men } \\
\hline Symptoms & 226 & 3420 & 66.1 & 1.00 & Ref. \\
\hline Any screening & 21 & 1371 & 15.3 & 0.38 & $(0.24-0.59)$ \\
\hline Other & 34 & 592 & 57.4 & 0.75 & $(0.52-1.08)$ \\
\hline \multicolumn{6}{|l|}{ Women } \\
\hline Symptoms & 147 & 2395 & 61.4 & 1.00 & Ref. \\
\hline Any screening & 11 & 672 & 16.4 & 0.45 & $(0.24-0.83)$ \\
\hline Other & 22 & 307 & 71.7 & 1.05 & $(0.66-1.67)$ \\
\hline \multicolumn{6}{|l|}{ Age $\leq 68$ years $^{b}$} \\
\hline Symptoms & 212 & 3574 & 59.3 & 1.00 & Ref. \\
\hline Any screening & 15 & 1231 & 12.2 & 0.38 & $(0.22-0.65)$ \\
\hline Other & 24 & 499 & 48.1 & 0.72 & $(0.46-1.12)$ \\
\hline \multicolumn{6}{|l|}{ Age $>68$ years $^{b}$} \\
\hline Symptoms & 161 & 2241 & 71.8 & 1.00 & Ref. \\
\hline Any screening & 17 & 812 & 20.9 & 0.43 & $(0.26-0.72)$ \\
\hline Other & 32 & 400 & 80.0 & 0.92 & $(0.63-1.35)$ \\
\hline
\end{tabular}

FOBT, faecal occult blood test; HR, hazard ratio. 95\% CI, 95\% confidence interval

${ }^{a}$ Adjusted for age, sex, education, stage and location of the cancer, and for time-dependent effects of age, sex, stage and location.

${ }^{\mathrm{b}}$ Age categorized at the median value

nodes. Relevant residual confounding by differences in tumor spread therefore appears unlikely. Second, more slowly growing cancers with more favourable prognosis might have a higher chance to be detected by screening and might be overrepresented in screen-detected cancers compared to symptom-detected cancers, a phenomenon known as "length time bias". Third, patients adherent to screening recommendations whose cancer was detected by screening might also be more adherent to therapy and might also otherwise behave more health conscious after diagnosis than patients with symptom-detected cancers. However, given that our findings persisted after control for education and given the similarity of non-CRC mortality among screen-detected and symptom-detected cancers, a major role of such "healthy screenee bias" seems unlikely.

Regardless of its origin, our findings of very favourable prognosis of screen-detected cancer cases might have important clinical and public health implications. First, the fear of a fatal diagnosis might prevent many people from using screening offers. Data showing that their prognosis is very good even in the unlikely case that a cancer is found at screening might help to alleviate such fears and enhance adherence to screening recommendations.
Second, direct evidence of relatively favorable prognosis may likewise alleviate fears of patients after a screening initiated diagnosis. Cancer patients are meanwhile often well informed on overall and stage specific cancer survival rates from internet or other information sources. Such survival rates typically do not differentiate between screen-detected and other cancers and may unduly discourage patients with screen-detected cancers. Knowledge of the true prognosis of patients with screen-detected cancers is equally important for the treating physicians and patient-physician interactions, as perspectives of survival and treatment success may impact on treatment decisions. There is ongoing active search for prognostic markers that may support judgment of prognosis as a basis for individual (personalized) treatment decisions. Our results suggest that mode of detection is an exceptionally informative marker in this context which is typically readily available or can be obtained at virtually no extra efforts and costs.

Our study has a number of strengths and limitations. To our knowledge, this is the first study simultaneously assessing and comparing survival outcomes of patients with screening colonoscopy detected CRC, FOBTdetected CRC and symptom-detected CRC, with and 
without stratification by and adjustment for cancer stage as well as a number of other relevant prognostic factors. Patients were recruited after diagnosis, in most cases during hospital stay or early after discharge. As a result, patients with very early deaths or too sick to participate are likely to be underrepresented. This might have increased observed absolute survival proportions to some extent but should not have affected hazard ratios comparing survival between patient groups. Causes of death were extracted from death certificates which are known to be prone to imprecision and coding errors. However, the validity of recorded cause of death has been consistently found to be much higher for cancers than for other causes of death [26]. Despite the large overall sample size, the limited numbers of deaths in some of the subgroup-specific analyses went along with rather wide confidence intervals. Our data do also not allow disentangling and quantifying the various factors other than earlier stage at diagnosis that might have contributed to the more favorable prognosis of screen-detected cancers. Although we controlled for multiple possible confounders, residual confounding by less than perfectly measured confounders or factors not controlled for cannot be ruled out.

Despite these limitations, our results have important practical implications. Physicians and patients should be aware of the very favorable prognosis after a screendetected CRC and take this important prognostic factor into account in their treatment decisions. Communication of the favorable prognosis even in the rare case of CRC detection at screening, along with balanced communication of the protective effects [1-11] and the (albeit rare) potential harms of CRC screening, such as bleedings after polypectomy or overdiagnoses [13, 27], might help to enhance acceptance of and adherence to this powerful preventive measure.

\section{ACKNOWLEDGMENTS}

\section{Authorship statement}

(i) Guarantor of the article: Hermann Brenner

(ii) Specific author contributions: Hermann Brenner designed the study, conducted the literature review and wrote the manuscript. Michael Hoffmeister conducted the statistical analysis. All authors contributed to data collection, data interpretation and manuscript revision.

(iii) All authors approved the final version of the manuscript.

We are grateful to study participants and the interviewers who collected the data. We would like to thank the following hospitals and cooperating institutions which recruited patients for this study:

Chirurgische Universitätsklinik Heidelberg, Klinik am Gesundbrunnen Heilbronn, Sankt Vincentiuskrankenhaus Speyer, Sankt Josefskrankenhaus Heidelberg, Chirurgische Universitätsklinik Mannheim,
Diakonissenkrankenhaus Speyer, Krankenhaus Salem Heidelberg, Kreiskrankenhaus Schwetzingen, Sankt Marien- und Sankt Annastiftkrankenhaus Ludwigshafen, Klinikum Ludwigshafen, Stadtklinik Frankenthal, Diakoniekrankenhaus Mannheim, Kreiskrankenhaus Sinsheim, Klinikum am Plattenwald Bad Friedrichshall, Kreiskrankenhaus Weinheim, Kreiskrankenhaus Eberbach, Kreiskrankenhaus Buchen, Kreiskrankenhaus Mosbach, Enddarmzentrum Mannheim, Kreiskrankenhaus Brackenheim, Cancer Registry of Rhineland-Palatinate, Mainz.

We would like to thank Ute Handte-Daub, Renate Hettler-Jensen, Petra Bächer, Ansgar Brandhorst and Utz Benscheid for excellent technical assistance.

\section{CONFLICTS OF INTEREST}

There is no conflict of interest.

\section{GRANT SUPPORT}

This work was supported by grants from the German Research Council (Deutsche Forschungsgemeinschaft, grant numbers BR 1704/6-1, BR 1704/6-3, BR 1704/6-4 and $\mathrm{CH} 117 / 1-1)$, and the German Federal Ministry of Education and Research (grant numbers 01KH0404 and 01ER0814). The sponsors had no role in study design, collection, analysis, and interpretation of the data and in the writing of the report.

\section{REFERENCES}

1. Hewitson P, Glasziou P, Watson E, Towler B, Irwig L. Cochrane systematic review of colorectal cancer screening using the fecal occult blood test (hemoccult): an update. Am J Gastroenterol 2008;103:1541-1549.

2. Scholefield JH, Moss SM, Mangham CM, Whynes DK, Hardcastle JD. Nottingham trial of faecal occult blood testing for colorectal cancer: a 20-year follow-up. Gut 2012;61:1036-1040

3. Shaukat A, Mongin SJ, Geisser MS, Lederle FA, Bond JH, Mandel JS, Church TR. Long-term mortality after screening for colorectal cancer. N Engl J Med 2013;369:1106-1114.

4. Atkin WS, Edwards R, Kralj-Hans I, Wooldrage K, Hart AR, Northover JM, Parkin DM, Wardle J, Duffy SW, Cuzick J; UK Flexible Sigmoidoscopy Trial Investigators. Once-only flexible sigmoidoscopy screening in prevention of colorectal cancer: a multicentre randomised controlled trial. Lancet 2010;375:1624-1633.

5. Segnan N, Armaroli P, Bonelli L, Risio M, Sciallero S, Zappa M, Andreoni B, Arrigoni A, Bisanti L, Casella C, Crosta C, Falcini F, Ferrero F, et al. Once-only sigmoidoscopy in colorectal cancer screening: Follow-up findings of the Italian Randomized Controlled Trial SCORE. J Natl Cancer Inst 2011;103:1310-1322. 
6. Schoen RE, Pinsky PF, Weissfeld JL, Yokochi LA, Church T, Laiyemo AO, Bresalier R, Andriole GL, Buys SS, Crawford ED, Fouad MN, Isaacs C, Johnson $\mathrm{CC}$, et al. Colorectal-cancer incidence and mortality with screening flexible sigmoidoscopy. N Engl J Med 2012;366:2345-2357.

7. Holme Ø, Løberg M, Kalager M, Bretthauer M, Hernán MA, Aas E, Eide TJ, Skovlund E, Schneede J, Tveit KM, Hoff G. Effect of flexible sigmoidoscopy screening on colorectal cancer incidence and mortality. JAMA 2014;312:606-615.

8. Zauber AG, Winawer SJ, O'Brien MJ, Lansdorp-Vogelaar I, van Ballegooijen M, Hankey BF, Shi W, Bond JH, Schapiro M, Panish JF, Stewart ET, Waye JD. Colonoscopic polypectomy and long-term prevention of colorectal-cancer deaths. N Engl J Med 2012;366:687-696.

9. Brenner H, Stock C, Hoffmeister M. Effect of screening sigmoidoscopy and screening colonoscopy on colorectal cancer incidence and mortality: systematic review and metaanalysis of randomised controlled trials and observational studies. BMJ 2014;348:g2467.

10. Brenner H, Chang-Claude J, Seiler CM, Rickert A, Hoffmeister M. Protection from colorectal cancer after colonoscopy: population-based case-control study. Ann Intern Med 2011;154:22-30.

11. Brenner H, Chang-Claude J, Jansen L, Knebel P, Stock C, Hoffmeister M. Reduced risk of colorectal cancer up to 10 years after screening surveillance or diagnostic colonoscopy. Gastroenterology 2014;146:709-717.

12. Hoffmeister M, Jansen L, Rudolph A, Toth C, Kloor M, Roth W, Bläker H, Chang-Claude J, Brenner H. Statin use and survival after colorectal cancer: the importance of comprehensive confounder adjustment. J Natl Cancer Inst 2015; 107:djv045.

13. Pox C, Altenhofen L, Brenner H, Theilmeier A, von Stillfried D, Schmiegel W. Efficacy of a nationwide screening colonoscopy program for colorectal cancer. Gastroenterology 2012;142:1460-1467.

14. Logan FA, Patnick J, Nickerson C, Coleman L, Rutter MD, von Wagner C; English Bowel Cancer Screening Evaluation Committee. Outcomes of the bowel cancer screening programme (BCSP) in England after the first million tests. Gut 2012;61:1439-1446.

15. Cole SR, Tucker GR, Osborne JM, Byrne SE, Bampton PA, Fraser RJ, Young GP. Shift to earlier stage at diagnosis as a consequence of the National Bowel Cancer Screening Program. Med J Aust 2013;198:327-330.

16. Lindebjerg J, Osler M, Bisgaard C. Colorectal cancers detected through screening are associated with lower stages and improved survival. Dan Med J 2014;61:A4758.
17. Parente F, Vailati C, Boemo C, Bonoldi E, Ardizzoia A, Ilardo A, Tortorella F, Cereda D, Cremaschini M, Moretti R. Improved 5-year survival of patients with immunochemical faecal blood test-screen-detected colorectal cancer versus non-screening cancers in northern Italy. Dig Liver Dis 2015;47:68-72.

18. Wada T, Saito H, Soma Y, Koeda J, Kawaguchi H, Tanaka M, Yoshida Y, Munakata A. Survival benefit for patients with colorectal cancer detected by population-based screening program using an immunochemical fecal occult blood test. Int J Oncol 1996;9:685-691.

19. Mapp TJ, Hardcastle JD, Moss SM, Robinson MH. Survival of patients with colorectal cancer diagnosed in a randomized controlled trial of faecal occult blood screening. Br J Surg 1999;86:1286-1291.

20. Rae LC, Gibberd RW. Survival of patients with colorectal cancer detected by a community screening program. Med J Aust 2000;172:13-15.

21. Morris EJA, Whitehouse LE, Farrell T, Nickerson C, Thomas JD, Quirke P, Rutter MD, Rees C, Finan PJ, Wilkinson JR, Patnick J. A retrospective observational study examining the characteristics and outcomes of tumours diagnosed within and without of the English NHS Bowel Screening Programme. Br J Cancer 2012;107:757-764.

22. Pande R, Froggatt P, Baragwanath P, Harmston C. Survival outcome of patients with screening versus symptomatically detected colorectal cancers. Colorectal Dis 2013;15:74-79.

23. Courtney ED, Chong D, Tighe R, Easterbrook JR, Stebbings WS, Hernon J. Screen-detected colorectal cancers show improved cancer-specific survival when compared with cancers diagnosed via the 2-week suspected colorectal cancer referral guidelines. Colorectal Dis 2013;15:177-182.

24. Gill MD, Bramble MG, Hull MA, Mills SJ, Morris E, Bradburn DM, Bury Y, Parker CE, Lee TJ, Rees CJ. Screendetected colorectal cancers are associated with an improved outcome compared with stage-matched interval cancers. Br J Cancer 2014;111:2076-2081.

25. Amri R, Bordeianou LG, Sylla P, Berger DL. Impact of screening colonoscopy on outcomes in colon cancer surgery. JAMA Surg 2013;148:747-754.

26. Klug SJ, Bardehle D, Ressing M, Schmidtmann I, Blettner M. [Comparison of ICD coding between mortality statistics and study-intern retrospective re-coding]. Gesundheitswesen 2009;71:220-5.

27. Brenner H, Altenhofen L, Stock C, Hoffmeister M. Prevention, early detection, and overdiagnosis of colorectal cancer within 10 years of screening colonoscopy in Germany. Clin Gastroenterol Hepatol 2015;13:717-23. 